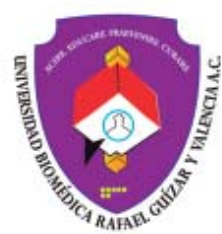

Vol. 8, Núm. 2

Julio-Diciembre 2021. pp. 63-65

doi: $10.35366 / 103083$

Editorial

\title{
¿Cómo evitar que el mito de Sísifo se replique en la educación biomédica actual?
}

\section{How to prevent the myth of Sisyphus to be reproduced in current biomedical education?}

\author{
Francisco Aguilar Rebolledo*
}

\section{RESUMEN}

Esta pandemia se convierte en una oportunidad para recordarnos las habilidades que nuestros estudiantes necesitan justo en crisis como éstas, siendo así, la toma de decisiones informada, resolución creativa de problemas y, sobre todo, adaptabilidad. Está en nuestras manos guiar ese proceso durante esta coyuntura y nueva realidad. «Búscate un propósito, Sísifo, márcate objetivos, trata de ponerte metas». Para garantizar que esas habilidades sigan siendo una prioridad para todos los alumnos, la resiliencia también debe integrarse en nuestros sistemas educativos.

Palabras clave: Educación biomédica, Sísifo, pandemia, nueva normalidad.

\section{ABSTRACT}

This pandemic becomes an opportunity to remind us of the skills that our students need right in crisis like these, thus, informed decision making, creative problem solving and, above all, adaptability. It is in our hands to guide that process during this juncture and new reality. «Find purpose for yourself, Sisyphus, set goals, try to set yourself goals». To ensure that those skills remain a priority for all students, resilience must also be built into our education systems.

Keywords: Biomedical education, Sisyphus, pandemic, new normality.

\section{INTRODUCCIÓN}

El mito de Sísifo es un ensayo escrito por Albert Camus en 1942, en él aborda el sentido de la existencia y afirma que si no hay un Dios que dé razón y sentido, la vida es absurda y cada uno puede hacer con ella lo que quiera. Para expresar sus ideas utiliza el mito griego de Sísifo, el cual cuenta la historia de un hombre que ofende a los dioses y es castigado a subir una roca hasta la cima de una montaña, con el infortunio de que ésta caerá por el poder de su peso y deberá subirla una y otra vez caída tras caída. El suceso más lamentable para Sísifo es ver caer la roca y hacerse consciente (Figura 1).

Es el absurdo del trabajo de un hombre, no obstante, lo vuelve a repetir. ${ }^{1}$ Camus nos enseña que sólo a través de la toma de conciencia de nuestra realidad y tomando la vida y las decisiones en nuestras manos podremos llegar a ser libres.

* Rector de la Universidad Biomédica Rafael Guízar y Valencia.

Correspondencia:

Acad. M en C Dr. Francisco Aguilar Rebolledo

E-mail: fran_aguilar_invest@yahoo.com.mx

Citar como: Aguilar RF. ¿Cómo evitar que el mito de Sísifo se replique en la educación biomédica actual? Plast Restaur Neurol. 2021;8 (2): 63-65. https://dx.doi.org/10.35366/103083

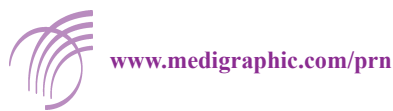




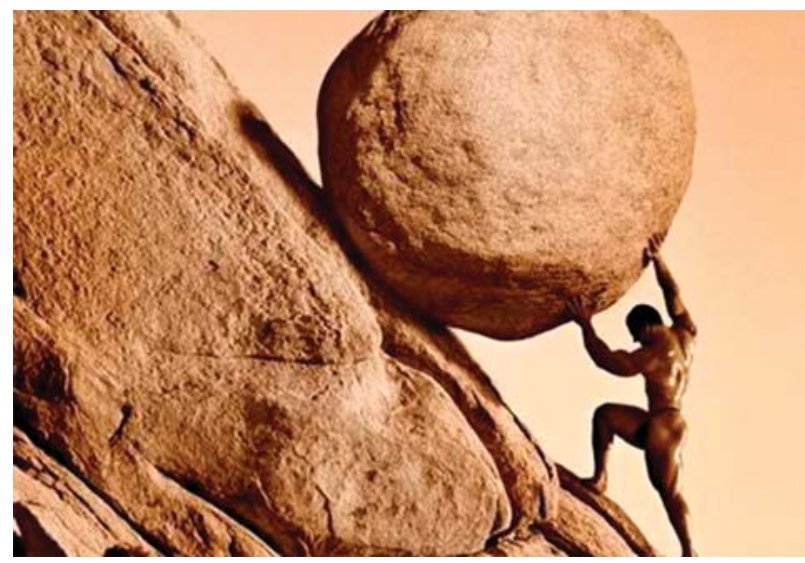

Figura 1: El mito de Sísifo nos hace reflexionar sobre el trabajo cotidiano sin esperanza. Por tanto nuestra visión deberá tener un objetivo y un sentido.

\section{DESARROLLO}

Específicamente para la educación biomédica, la conciencia y utilidad del proceso de aprendizaje están reforzadas por interactuar con los pacientes, retroalimentarse en la evaluación de pacientes, integrar un diagnóstico y proponer un tratamiento, en suma, participar de manera activa de la atención en salud. Al pasar abruptamente a la educación virtual remota, con contenidos carentes de práctica, muchos estudiantes han caído en el mito de Sísifo: inconscientes de la trascendencia y sentido de su aprendizaje, estudian para ganar exámenes y aprobar asignaturas.

Cuando se estudia únicamente para un examen, se fija inadecuadamente el conocimiento y se entra en una peligrosa relajación, que lleva a olvidar lo «aprendido». El cerebro, como componente indispensable de aprendizaje, permite ser estimulado a través la neuroeducación reconociendo los factores que inciden en el crecimiento, desarrollo y funcionamiento. La identificación y aplicación de estrategias cognitivas de aprendizaje permiten que el cerebro del ser humano se active e influya en el aprendizaje significativo, utilizando procedimientos como el de «aprender a aprender», estrategia que involucra un nuevo ciclo de estudio para alcanzar el aprendizaje significativo en el próximo examen. No sólo estudiar nuevamente para aprobar y olvidar los nuevos conocimientos. Así de esta forma cíclica puede mejorar el conocimiento aprendido (aprendizaje significativo). ${ }^{2}$

Nuestra realidad ha cambiado para siempre $y$, aunque algunas facultades vuelvan progresivamente a la presencialidad, ciertas asignaturas serán definitivamente virtuales.
En este sentido y entendiendo, la relación entre el mito de Sísifo y la nueva realidad de la educación médica, es oportuno responder esta interrogante:

- ¿Cómo evitar que el mito de Sísifo se replique en la educación médica actual? -.

Pues bien, la respuesta es: evaluación formativa.

La evaluación formativa, al no estar ligada a una calificación y ser un instrumento para la retroalimentación docente-estudiante, ${ }^{3}$ refuerza la conciencia de la importancia de aprender correctamente, aumenta la motivación, promueve la autoevaluación y la corrección de esquemas mal aprendidos y, lo más importante, permite desarrollar habilidades de por vida. Algunas de las características de la evolución formativa son:

1. Posibilita actuar sobre el sujeto que aprende, poniendo de manifiesto dónde se han producido los errores de aprendizaje si es que los hay.

2. Permite observar con claridad la trayectoria que sigue un estudiante entre su situación de partida y su situación de llegada, respecto del logro de sus objetivos de aprendizaje.

3. Es de carácter procesual y continua, porque permite reorientar prácticas de manera permanente.

4. Permite perfeccionar procesos y resultados de aprendizaje.

5. Se utiliza preferentemente como estrategia de mejora y para ajustar sobre la marcha los procesos educativos, en miras de conseguir las metas y objetivos previstos.

\section{DISCUSIÓN}

Es imperativo que los estudiantes de biomedicina sean conscientes del alcance de sus conocimientos (Terapia física y rehabilitación, psicología, nutrición, enfermería y optometría -tratar personas con conocimiento y suficiencia sin hacer daño por ineficiencia-), que reevalúen por qué están aprendiendo y cómo puede impactar su conocimiento a la humanidad. ${ }^{4}$ Los estudios que nos parecen importantes y que nos hacen sentir que lo somos son una fuente de significado en la vida, cosas a las que atribuimos valor, justificación ética o legitimidad.

Está en nuestras manos guiar ese proceso durante esta coyuntura y nueva realidad. «Búscate un propósito, Sísifo, márcate objetivos, trata de ponerte metas», «sé Unibio», «iqueremos ser el principio de tu historia, tu esfuerzo está logrando objetivos superiores!». 


\section{REFERENCIAS}

1. Salazar NJM. Un Sísifo inconsciente. El Dominical, El Comercio 2020.

2. Harari YN. Homo Deus. Breve historia del mañana. México D.F.: Pinguin Random House, 2016.
3. FrankI V. El hombre en busca de sentido. Barcelona: Herder. 2015.

4. Baumeister RF. The meanings of life. Aeon Essays, 2013. [Recuperado 16 Octubre 2013] Available in: https://aeon.co/ essays/what-is-better-a-happy-life-or-a-meaningful-one 